\title{
Second Law Analysis on an Air-Standard Miller Engine
}

\author{
R. EBRAHIMI* \\ Department of Mechanical Engineering of Biosystem, Shahrekord University, P.O. Box 115, Shahrekord, Iran \\ (Received April 14, 2015; in final form March 19, 2016)
}

\begin{abstract}
Performance analysis has been carried out for air-standard Miller engine using second law analysis. The relations of the second law efficiency versus compression ratio, the second law efficiency versus first law efficiency as well as the exergy versus compression ratio are obtained. The results show that the curve of second law efficiency versus first law efficiency is a parabolic-like one. The results also show that, throughout the compression ratio range, the second law efficiency increases when the expansion-compression ratio increases.
\end{abstract}

DOI: 10.12693/APhysPolA.129.1079

PACS/topics: 05.70.Ln, 82.60.Fa, 88.05.-b

\section{Introduction}

The Miller cycle was patented by Ralph Miller, an American engineer, in the 1940's [1]. The thermodynamics cycles have been put attention recently, and some authors have examined the finite-time thermodynamic performance of the Miller cycle [2-6]. Al-Sarkhi et al. [7] modeled the efficiency of a Miller engine in term of thermodynamics calculation. They found that the effects of the temperature-dependent specific heat of the working fluid on the cycle performance were significant and should have been considered in design. A slight increase in some parameter would have an impact on the thermal efficiency of the cycle. Chen et al. [8] built a class of generalized irreversible universal steady flow heat engine cycle model consisting of two heating branches, two cooling branches, and two adiabatic branches with consideration of the losses of heat resistance, heat leakage, and internal irreversibility. The performance characteristics of Diesel, Otto, Brayton, Atkinson, dual and Miller cycles were derived. Zhao and Chen [9] conducted a performance analysis on irreversible Miller cycle engine by considering internal irreversibilities of the Miller cycled engine. Lin and Hou [10] studied on an air-standard Miller cycle and analyzed the performance of the cycle taking into account friction losses, variable specific heats of the air and heat dissipation as a percentage of energy released from burnt fuel. Ebrahimi [11, 12] analyzed the performance of an air standard Miller cycle by using finite-time thermodynamics. The results show that if compression ratio is less than certain value, the power output decreases with increasing stroke length, while if compression ratio exceeds certain value, the power output first increases and then starts to decrease with increasing stroke length. The results are of importance to provide good guidance for the performance evaluation and improvement of practical Miller engines. Gonca et al. [13] studied the performance analysis based on the

\footnotetext{
*e-mail: Rahim.Ebrahimi@gmail.com
}

power output, thermal efficiency, maximum power output and maximum thermal efficiency for an air-standard irreversible dual-Miller cycle with late inlet valve closing version which covers internal irreversibility owing to the irreversible-adiabatic processes. Lin et al. [14] evaluated the performance of an irreversible air standard Miller cycle in a four-stroke free-piston engine by using finite-time thermodynamic. In the model, the relation between the internal irreversibility described by using the compression and expansion efficiencies, the specific heat of the working substance depending on its temperature, the heat transfer loss as a percentage of fuel's energy and the friction loss computed according to the mean velocity of the piston is considered.

As can be seen in the relevant literature, the investigations of the second law efficiency and exergy on the Miller cycle do not appear to have been published. Therefore, the objective of this study is to examine the second law efficiency and exergy on the air standard Miller cycle.

\section{Thermodynamic analysis}

The pressure-volume $(P-V)$ and the temperatureentropy $(T-S)$ diagrams of an irreversible Miller cycle is shown in Fig. 1, where $T_{1}, T_{2}, T_{3}, T_{4}$, and $T_{5}$ are the temperatures of the working substance in state points 1 , $2,3,4$, and 5 . The compression process is an isentropic process $1 \rightarrow 2$; the heat addition is an isochoric process $2 \rightarrow 3$; the expansion process is an isentropic process $3 \rightarrow 4$; and the heat rejection are an isochoric process $4 \rightarrow 5$ and an isobaric process $5 \rightarrow 1$.

The relations between the mass flow rate of the fuel $\left(\dot{m}_{\mathrm{f}}\right)$ and the mass flow rate of the air $\left(\dot{m}_{\mathrm{a}}\right)$, between $\dot{m}_{\mathrm{f}}$ and the mass flow rate of the air-fuel mixture $\left(\dot{m}_{\mathrm{t}}\right)$ are defined as [12]:$$
\dot{m}_{\mathrm{f}}=\varphi \dot{m}_{\mathrm{a}}\left(m_{\mathrm{f}} / m_{\mathrm{a}}\right)_{\mathrm{s}}
$$$$
\text { and }
$$$$
\dot{m}_{\mathrm{t}}=\dot{m}_{\mathrm{a}}\left[1+\varphi\left(m_{\mathrm{f}} / m_{\mathrm{a}}\right)_{\mathrm{s}}\right],
$$

where $m_{\mathrm{a}} / m_{\mathrm{f}}$ is the air-fuel ratio and the subscript $\mathrm{s}$ denotes stoichiometric conditions, $\varphi$ is the equivalence ratio.
} 

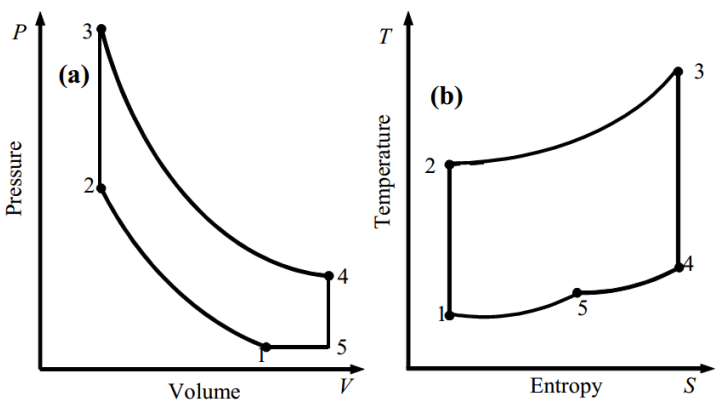

Fig. 1. (a) $P-V$ diagram; (b) $T-S$ diagram for the air standard Miller cycle.

The expansion-compression ratio, $\psi$, the effective compression ratio, $r_{\mathrm{c}}^{*}$, and the compression ratio, $r_{\mathrm{c}}$, are defined as:

$$
\begin{aligned}
& \psi=\frac{V_{5}}{V_{1}}=\frac{T_{5}}{T_{1}}, \\
& r_{\mathrm{c}}^{*}=\frac{V_{1}}{V_{2}},
\end{aligned}
$$

and

$$
r_{\mathrm{c}}=\frac{V_{5}}{V_{2}}=\psi r_{\mathrm{c}}^{*} .
$$

Therefore, for processes $(1 \rightarrow 2)$ and $(3 \rightarrow 4)$, we have

$$
T_{2}=T_{1}\left(\frac{r_{\mathrm{c}}}{\psi}\right)^{\gamma-1}
$$

and

$$
T_{4}=T_{3} r_{\mathrm{c}}^{1-\gamma} \text {. }
$$

For an ideal Miller cycle model, there are no losses. However, for a real Miller engine cycle, the heat transfer irreversibility between the working fluid and the cylinder wall is not negligible. It is assumed that the heat loss through the cylinder wall is proportional to the average temperature of the working fluid and the cylinder wall, and that, during the steady state operation, the wall temperature remains approximately invariant. The energy transferred to the working fluid during combustion is given by the following linear relation [7-12]:

$$
\begin{aligned}
& \dot{Q}_{\text {in }}=\eta_{\mathrm{c}} \varphi \dot{m}_{\mathrm{a}}\left(m_{\mathrm{f}} / m_{\mathrm{a}}\right)_{\mathrm{s}} Q_{\mathrm{LHV}} \\
& \quad-\dot{m}_{\mathrm{a}} B\left(1+\varphi\left(m_{\mathrm{f}} / m_{\mathrm{a}}\right)_{\mathrm{s}}\right)\left(T_{2}+T_{3}-2 T_{0}\right),
\end{aligned}
$$

where $B$ is constant related to heat transfer. From Eq. (8), it can be seen that $Q_{\text {in }}$ contained two parts: the first part is $\eta_{\mathrm{c}} \varphi \dot{m}_{\mathrm{a}}\left(m_{\mathrm{f}} / m_{\mathrm{a}}\right)_{\mathrm{s}} Q_{\mathrm{LHV}}$, the released heat by combustion per second, and the second part is the heat leakage loss per second, $Q_{\text {leak }}=$ $\dot{m}_{\mathrm{a}} B\left(1+\varphi\left(m_{\mathrm{f}} / m_{\mathrm{a}}\right)_{\mathrm{s}}\right)\left(T_{2}+T_{3}-2 T_{0}\right)$.

The heat added to the working fluid during the heat addition process $2 \rightarrow 3$ is

$$
\begin{aligned}
& \dot{Q}_{\text {in }}=\dot{m}_{\mathrm{t}} c_{v}\left(T_{3}-T_{2}\right)= \\
& \quad \frac{\dot{m}_{\mathrm{a}} R}{\gamma-1}\left(1+\varphi\left(m_{\mathrm{f}} / m_{\mathrm{a}}\right)_{\mathrm{s}}\right)\left(T_{3}-T_{2}\right)
\end{aligned}
$$

where $T$ is the absolute temperature and $\gamma$ is the specific heat ratio for the working fluid.
The heat rejected per second by the working fluid during processes $4 \rightarrow 5$ and $5 \rightarrow 1$ is

$$
\begin{aligned}
& \dot{Q}_{\text {in }}=\dot{m}_{\mathrm{t}} c_{v}\left(T_{4}-T_{5}\right)+\dot{m}_{\mathrm{t}} c_{p}\left(T_{5}-T_{1}\right)= \\
& \quad \frac{\dot{m}_{\mathrm{a}} R}{\gamma-1}\left(1+\varphi\left(m_{\mathrm{f}} / m_{\mathrm{a}}\right)_{\mathrm{s}}\right)\left[T_{4}-T_{5}+\gamma\left(T_{5}-T_{1}\right)\right] .
\end{aligned}
$$

The first law efficiency of the cycle is

$$
\begin{aligned}
& \eta_{\mathrm{I}}=\frac{\dot{Q}_{\text {in }}-\dot{Q}_{\text {out }}}{\dot{Q}_{\text {in }}} \times 100= \\
& \quad\left(1-\frac{T_{4}-T_{5}+\gamma\left(T_{5}-T_{1}\right)}{T_{3}-T_{2}}\right) \times 100 .
\end{aligned}
$$

The following definition is used for the second law efficiency [15]:

$$
\begin{aligned}
& \eta_{\mathrm{II}}=\frac{\text { Exergy out }(\text { as work transfer })}{\text { Exergy in }}= \\
& \frac{T_{3}-T_{2}+T_{5}-T_{4}+\gamma\left(T_{1}-T_{5}\right)}{T_{3}-T_{1}} \times 100 .
\end{aligned}
$$

The availability of a system in a given thermodynamic state is defined as the maximum useful mechanical work that can be produced as the system is brought to thermal, mechanical, and chemical equilibrium with its environment through reversible processes $[16,17]$.

The change in availability (or exergy) for closed systems can be found by summing thermomechanical and chemical exergies [16]:

$$
\begin{aligned}
& \mathrm{d} A=\mathrm{d} A_{\mathrm{th}}+\mathrm{d} A_{\mathrm{fch}}=\left(U_{j}-U_{i}\right)+P_{0}\left(V_{j}-V_{i}\right) \\
& \quad-T_{0}\left(S_{j}-S_{i}\right)+\left(m_{\mathrm{fj}}-m_{\mathrm{fi}}\right) a_{\mathrm{fch}} .
\end{aligned}
$$

Here, $a_{\mathrm{fch}}$ is the fuel chemical exergy, $a_{\mathrm{fch}}$ is calculated by using the following equation for liquid fuels [18]:

$$
a_{\mathrm{fch}}=(1.0286+0.0008) Q_{\mathrm{LHV}} \text {. }
$$

An exergy analysis for each process in the ideal cycle was examined. Exergy balance equations are derived with consideration of heat transfer loss in this paper. The compression process is isentropic, so

$$
\begin{aligned}
& A_{21}=\left(U_{2}-U_{1}\right)+P_{1}\left(V_{2}-V_{1}\right)= \\
& \quad R \dot{m}_{\mathrm{a}}\left(1+\varphi\left(m_{\mathrm{f}} / m_{\mathrm{a}}\right)_{\mathrm{s}}\right)\left(\frac{T_{3}-T_{2}}{\gamma-1}+\frac{\psi T_{1}}{r_{\mathrm{c}}-T_{1}}\right) .
\end{aligned}
$$

During combustion, for the constant-volume cycle, the volume and internal energy remain unchanged. Thus

$$
\begin{aligned}
& A_{32}=\left(U_{3}-U_{2}\right)-T_{1}\left(S_{3}-S_{2}\right)+\left(m_{\mathrm{f} 3}-m_{\mathrm{f} 2}\right) a_{\mathrm{fch}}= \\
& \frac{\dot{m}_{\mathrm{a}} R}{\gamma-1}\left(1+\varphi\left(m_{\mathrm{f}} / m_{\mathrm{a}}\right)_{\mathrm{s}}\right)\left(T_{3}-T_{2}-T_{1} \ln \left(\frac{T_{3}}{T_{2}}\right)\right) \\
& -\varphi \dot{m}_{\mathrm{a}}\left(m_{\mathrm{f}} / m_{\mathrm{a}}\right)_{\mathrm{s}} a_{\mathrm{fch}} .
\end{aligned}
$$

For the expansion stroke

$$
\begin{aligned}
& A_{43}=\left(U_{4}-U_{3}\right)+P_{1}\left(V_{4}-V_{3}\right)=m_{\mathrm{t}} c_{v}\left(T_{4}-T_{3}\right) \\
& \quad+m_{\mathrm{t}} R\left[\psi T_{1}-\left(\frac{r_{\mathrm{c}}}{\psi}\right)^{-\gamma} T_{2}\right] .
\end{aligned}
$$

The exergy changes for processes $4 \rightarrow 5$ and $5 \rightarrow 1$ are given by

$$
A_{54}=\left(U_{5}-U_{4}\right)-T_{1}\left(S_{5}-S_{4}\right)=m_{\mathrm{t}} c_{v}\left(T_{5}-T_{4}\right)
$$




$$
\begin{aligned}
& -m_{\mathrm{t}} T_{1} c_{v} \ln \left(\frac{T_{5}}{T_{4}}\right), \\
& A_{15}=\left(U_{1}-U_{5}\right)+P_{1}\left(V_{1}-V_{5}\right)-T_{1}\left(S_{1}-S_{5}\right)= \\
& m_{\mathrm{t}} T_{1}\left[c_{p}(1-\psi)-c_{v} \ln \left(\frac{1}{\psi}\right)\right]+m_{\mathrm{f}} a_{\mathrm{fch}} .
\end{aligned}
$$

When $r_{c}^{*}, \psi$ and $T_{1}$ are given, $T_{2}$ can be obtained from Eq. (13); then, substituting from Eq. (3) into Eq. (15) yields $T_{3}$; and $T_{4}$ can be found from Eq. (14); at last, $T_{5}$ can be found by Eq. (12). Substituting $T_{1}, T_{2}, T_{3}, T_{4}$, and $T_{5}$ into Eqs. (19) and (20), respectively, the first and second law thermodynamic can be obtained. Also, substituting $T_{1}, T_{2}, T_{3}, T_{4}$, and $T_{5}$ into Eqs. (19),(20), the exergy changes and exergy for each process or state can be calculated. It should be noted here that the exergy at state 1 is equal to exergy of the fuel.

\section{Numerical examples and discussion}

The following constants and parameters have been used in this exercise: $T_{1}=300 \mathrm{~K}, B=1.1 \mathrm{~J} \mathrm{~kg}^{-1} \mathrm{~K}^{-1}$, $Q_{\mathrm{LHV}}=44 \mathrm{MJ} \mathrm{kg}^{-1}, \varphi=1, \eta_{\mathrm{c}}=100 \%, \gamma=1.35$, $\left(m_{\mathrm{a}} / m_{\mathrm{f}}\right)_{\mathrm{s}}=14.6, \quad R=0.287 \mathrm{~kJ} \mathrm{~kg}^{-1}$ and $m_{\mathrm{a}}=$ $0.0146 \mathrm{~kg} \mathrm{~s}^{-1}[7-12,19,20]$. Using the above constants and ranges of parameters, the second law efficiency versus compression ratio characteristic, the second law efficiency versus first law efficiency characteristic and the exergy versus compression ratio characteristic can be plotted as in Figs. 2-4 (The dashed lines in the figures denote where the cycle cannot work on, when $T_{5}$ exceeds $T_{4}$.) They reflect the performance characteristics of a real irreversible Miller cycle. Numerical examples are shown as follows.

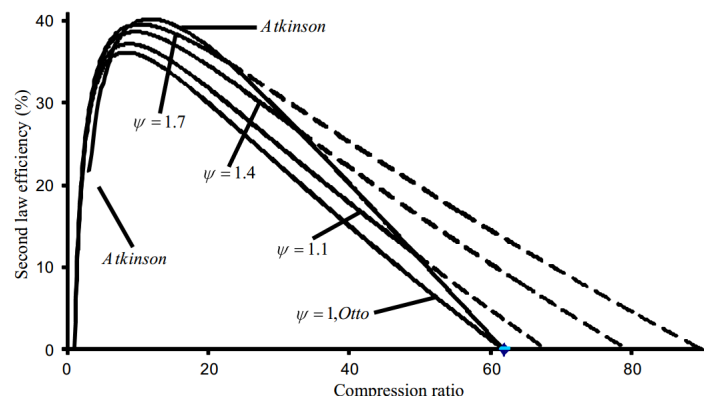

Fig. 2. Effect of expansion-compression ratio on the variation of the second law efficiency with compression ratio.

Figures 2, 3 show the effect of expansion-compression ratio on the second law efficiency. From these figures, it can be found that the expansion-compression ratio plays important roles on the performance cycle. It is clearly seen that the effect of expansion-compression ratio on the second law efficiency is related to compression ratio. The second law efficiency versus the first law efficiency characteristic and the second law efficiency versus the combustion ratio characteristic are parabolic-like

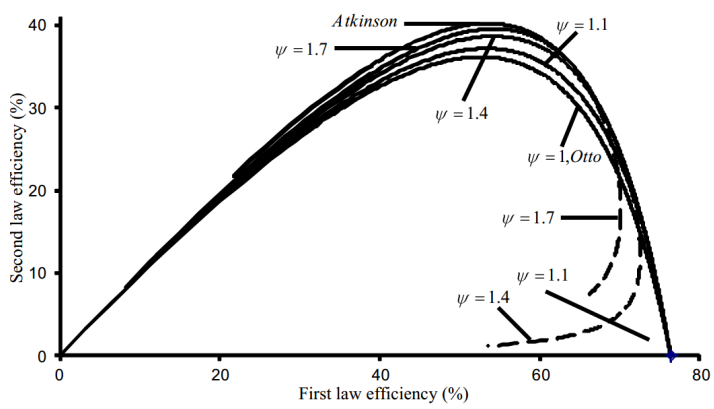

Fig. 3. Effect of expansion-compression ratio on the variation of the second law efficiency with first law efficiency.

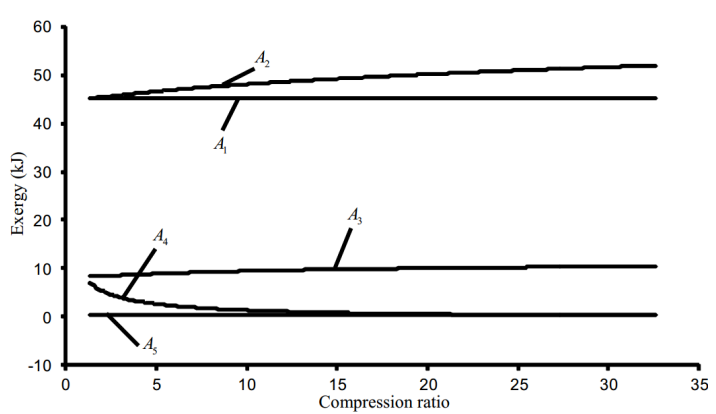

Fig. 4. Exergy versus compression ratio.

curves. Figure 2 shows that, throughout the compression ratio range, the second law efficiency increases when the expansion-compression ratio increases. This is due to the increase of the heat added by the working fluid being more than the increase of the heat rejected by the working fluid. In other words, the difference between heat added and heat rejected increases with increase of the expansion-compression ratio. When expansioncompression ratio increases, the range of compression ratio in which the cycle can work normally will become smaller. Numerical calculation shows that for any same compression ratio, the largest second law efficiency is for Miller when $r_{\mathrm{c}} \leq 9$, is for Atkinson when $r_{\mathrm{c}}>9$ and the smallest second law efficiency is for Atkinson when $r_{\mathrm{c}} \leq 6.1$ and is for Otto when $r_{\mathrm{c}}>6.1$. It can be seen from Figs. 2 and 3 that the maximum second law efficiency, the optimal compression ratio corresponding to maximum second law efficiency point and the optimal first law efficiency corresponding to maximum second law efficiency point increase when expansion-compression ratio increases while the working range of the cycle decreases with increase of expansion-compression ratio. Therefore, for a real Miller cycle, one can choose a proper expansion-compression ratio by adjusting the angle of the inlet valve opening and closing to improve the engine performance.

Figure 4 shows exergy at state points $1-5$ versus compression ratio. It can be concluded from Fig. 4 that, throughout the compression ratio range, the exergy at state 1 remains constant and equal to exergy of the fuelair mixture. The exergy at state point 2 is higher than 
that at state point 1 throughout the compression ratio range. This is because of work done on the working fluid during compression stroke. The exergy at state point 2 increases with increasing compression ratio, while the increasing rate of exergy at state point 2 decreases with increasing compression ratio. This can be attributed to the fact that the temperature at state point 2 increase with increase of compression ratio, while the rate of increase temperature at state 2 decreases with increasing compression ratio. Throughout the compression ratio range, the exergy at state 3 is lower than that at state 2 due to the destruction of exergy during combustion stroke. The exergy at state 3 increases with increasing compression ratio, while the increasing rate of exergy at state 3 decreases with increasing compression ratio. This is due to the fact that, when the compression ratio increased, the increasing exergy at state 2 is greater than increasing destruction of exergy during the combustion stroke. Throughout the compression ratio range, the exergy at state 4 is lower than that at state 3 due to work done on the piston during the expansion stroke by the working fluid. The exergy at state 4 decreases with increasing compression ratio, while the decreasing rate of exergy at state 4 increases with increasing compression ratio. This is due to the fact that the variation of temperature at state 4 is similar with variation of exergy at state 4 . The exergy at state 5 is lower than that at state 4 due to heat rejected. The exergy at state 1 is higher than that at state 5 . This is due to the fact that the fuel is added to working fluid at state 1 .

\section{Conclusion}

In this study finite-time thermodynamics analysis of an air standard Miller cycle is established which is closer to practice engine. The performance characteristics of the cycle were obtained by detailed numerical examples. The relations of the second law efficiency versus compression ratio, the second law efficiency versus first law efficiency as well as the exergy versus compression ratio are obtained. The results show that for a real Miller cycle, one can choose a proper expansion-compression ratio by adjusting the angle of the inlet valve opening and closing to improve the engine performance. The exergy cycle is influenced by the compression ratio. The results of this investigation are of importance when considering the designs of Miller engines.

\section{References}

[1] R.H. Miller, ASME Trans. 69, 453 (1947).

[2] R. Ebrahimi, Acta Phys. Pol. A 118, 534 (2010).

[3] R. Ebrahimi, Acta Phys. Pol. A 120, 384 (2011).

[4] A. Al-Sarkhi, I. Al-Hinti, E. Abu-Nada, B. Akash, Int. Commun. Heat Mass 3, 897 (2007).

[5] R. Ebrahimi, Acta Phys. Pol. A 124, 6 (2013).

[6] R. Ebrahimi, Acta Phys. Pol. A 122, 645 (2012).

[7] A. Al-Sarkhi, J.O. Jaber, S.D. Probert, Appl. En. 83, 343 (2006).

[8] L. Chen, W. Zhang, F. Sun, Appl. En. 84, 512 (2007).

[9] Y. Zhao, J. Chen, Appl. Therm. Eng. 27, 2051 (2007).

[10] J.C. Lin, S.S. Hou, Int. J. Therm. Sci. 47, 182 (2008).

[11] R. Ebrahimi, Comput. Math. Appl. 62, 2169 (2011).

[12] R. Ebrahimi, Appl. Math. Mod. 36, 4073 (2012).

[13] G. Gonca, B. Sahin, Y. Ust, Energy 54, 285 (2013).

[14] J. Lin, Z. Xu, S. Chang, H. Yan, Int. Commun. Heat Mass 54, 54 (2014).

[15] I. Sezer, A. Bilgin, Fuel 112, 523 (2013).

[16] J.B. Heywood, Internal Combustion Engine Fundamentals, McGraw Hill, New York 1988.

[17] G.R. Fatehi, Sh. Khalilarya, R. Ebrahimi, Therm. Sci. 17, 107 (2013).

[18] H. Ozcan, Heat Mass Transf. 47, 571 (2011).

[19] R. Ebrahimi, Sci. Iran. 18, 1231 (2011).

[20] R. Ebrahimi, M. Mercier, IJE Trans. B Appl. 24, 65 (2011). 